\title{
Otitis Media Supuratif Kronik di Poliklinik THT-KL RSUP Prof. Dr. R. D. Kandou Manado Periode Januari 2014 - Desember 2016
}

\author{
${ }^{1}$ Debora M. Pangemanan, \\ ${ }^{2}$ Oraetlabora I. Palandeng, \\ ${ }^{2}$ Olivia C. P. Pelealu
}
${ }^{1}$ Program Studi Pendidikan Dokter Fakultas Kedokteran Universitas Sam Ratulangi Manado
${ }^{2}$ Bagian Ilmu THT-KL Fakultas Kedokteran Universitas Sam Ratulangi Manado
Email: monicapangemanan@yahoo.com

\begin{abstract}
Chronic suppurative otitis media is an inflammatory process caused by mucoperiosteum infection in the middle ear cavity marked by tympanic membrane perforation. This study was aimeds to obtain the profile of chronic suppurative otitis media at Prof. Dr. R. D. Kandou Hospital Manado form January 2014 to December 2016. This was a descriptive retrospective study using medical record data. The results showed that there were 78 cases diagnosed as chronic suppurative otitis media; 30 cases (38\%) were 18-40 years old. There was no difference in number by gender. Location of this disease was more often unilateral. Otorrhea was the clinical symptom found in $87 \%$ of patients, followed by otalgia and hearing disturbance. Drug treatment was the most used treatment. Conclusion: Chronic suppurative otitis media was most common in age 18-40 years and there was no difference between sexes. Otorrhea was the most frequent clinical symptom. Most cases had unilateral otitis media and treated with medical treatment.
\end{abstract}

Keywords: chronic suppurative otitis media, age, gender, clinical symptoms

\begin{abstract}
Abstrak: Otitis media supuratif kronik (OMSK) merupakan proses peradangan yang disebabkan oleh infeksi mukoperiosteum dalam rongga telinga tengah yang ditandai oleh perforasi membran timpani. Penelitian ini bertujuan untuk mengetahui gambaran umum penderita OMSK di RSUP Prof. Dr. R. D. Kandou Manado periode Januari 2014 - Desember 2016. Jenis penelitian ini ialah deskriptif retrospektif menggunakan data rekam medis. Hasil penelitian mendapatkan 78 kasus dengan diagnosis OMSK, terbanyak didapatkan pada tahun 2016, diikuti tahun 2015 dan 2014. Kelompok usia 18-40 tahun yang terbanyak menderita OMSK, yaitu sebanyak 30 kasus (38\%). Tidak ada perbedaan jumlah penderita berdasarkan jenis kelamin. Otore merupakan gejala klinik yang ditemukan pada $87 \%$ penderita, diikuti oleh otalgia dan pendengaran berkurang. Lokasi sering terjadi pada salah satu telinga. Penanganan medika mentosa ialah penanganan yang paling sering dilakukan. Simpulan: OMSK terbanyak didapatkan pada usia 18-40 tahun dan tidak terdapat perbedaan pada kedua jenis kelamin. Otore merupakan gejala klinik yang paling sering. Umumnya lokasi OMSK unilateral dan jenis penanganan tersering ialah medikamentosa.
\end{abstract}

Kata kunci: otitis media supuratif kronik, usia, jenis kelamin, gejala klinik

Otitis media supuratif kronik (OMSK) merupakan proses peradangan yang disebabkan oleh infeksi mukoperiosteum pada rongga telinga tengah yang ditandai oleh perforasi membran timpani disertai dengan keterlibatan mukosa telinga tengah dan juga rongga pneumatisasi di daerah tulang temporal, keluarnya sekret yang terus menerus atau hilang timbul, dan dapat menyebabkan perubahan patologik yang permanen. ${ }^{1,2}$

Otitis media supuratif kronik terbagi atas dua bagian berdasarkan ada tidaknya kolesteatom yaitu OMSK benigna dan 
maligna. ${ }^{3,4}$ OMSK benigna adalah proses peradangan yang terbatas pada mukosa, tidak mengenai tulang, peforasi terletak di sentral, dan tidak terdapat kolesteatom. Umumnya OMSK tipe ini jarang menimbulkan komplikasi yang berbahaya. OMSK maligna ialah peradangan yang disertai kolesteatom dan perforasi membran timpani biasanya terletak di marginal atau atik. Sebagian besar komplikasi yang berbahaya dapat timbul pada tipe ini. ${ }^{5}$

Menurut World Health Organization (WHO), diperkirakan OMSK memiliki angka kejadian sebanyak 65-330 juta di seluruh dunia; $60 \%$ di antaranya mengalami gangguan pendengaran. ${ }^{6}$ Otitis media supuratif kronik merupakan penyakit THT yang paling banyak di negara sedang berkembang sedangkan di negara maju seperti Inggris sekitar 0,9\% dan di Israel hanya $0,0039 \%$. Di negara berkembang dan negara maju prevalensi OMSK berkisar antara $1-46 \%{ }^{7}$

Insiden OMSK bervariasi di setiap negara berkembang. Secara umum, insiden dipengaruhi oleh berbagai faktor seperti ras dan faktor sosioekonomi. Kehidupan sosioekonomi yang rendah, lingkungan kumuh dan status kesehatan serta gizi yang buruk merupakan faktor resiko yang mendasari peningkatan prevalensi OMSK di negara berkembang. ${ }^{8,9}$

Di Indonesia, menurut Survei Kesehatan Indera Penglihatan dan Pende-ngaran Depkes tahun 1993-1996 prevalensi OMSK ialah $3,1 \%-5,2 \%$ populasi. Usia penderita infeksi telinga tengah tersering ialah 7-18 tahun, dan penyakit telinga tengah terbanyak ialah OMSK.

Otitis media supuratif kronik di dalam masyarakat Indonesia dikenal dengan istilah congek atau telinga berair. Kebanyakan penderita OMSK menganggap penyakit ini merupakan penyakit yang biasa dan nantinya akan sembuh sendiri. Penelitian ini bertujuan untuk mendapatkan profil penderita Otitis Media Supuratif Kronik di Poliklinik THT-KL RSUP Prof. Dr. R. D. Kandou Manado periode Januari 2014 - Desember 2016.

\section{METODE PENELITIAN}

Jenis penelitian ini ialah retrospektif deskriptif yang dilakukan di Poliklinik THT-KL RSUP dan Instalasi Rekam Medik RSUP Prof. Dr. R. D. Kandou Manado pada bulan Oktober - November 2017.

Populasi ialah pasien yang berobat di Poliklinik THT-KL RSUP Prof. Dr. R. D. Kandou Manado periode Januari 2014Desember 2016 sedangkan sampel ialah pasien yang terdiagnosis OMSK pertama kali (baru) di Poliklinik THT-KL RSUP Prof. Dr. R. D. Kandou Manado pada periode tersebut.

Data penellitian diperoleh dari status penderita dan buku register di Poliklinik THT-KL KSM RSUP Prof. Dr. R. D. Kandou Manado periode Januari 2014Desember 2016. Data diolah dan disajikan dalam bentuk tabel.

\section{HASIL PENELITIAN}

Berdasarkan hasil penelitian yang telah dilakukan di Poliklinik THT-KL RSUP Prof. Dr. R. D. Kandou Manado selama periode 3 tahun (2014-2016), didapatkan sebanyak 78 penderita yang datang ke Poliklinik THT-KL RSUP Prof Dr. R. D. Kandou Manado dan didiagnosis dengan OMSK (Gambar 1).

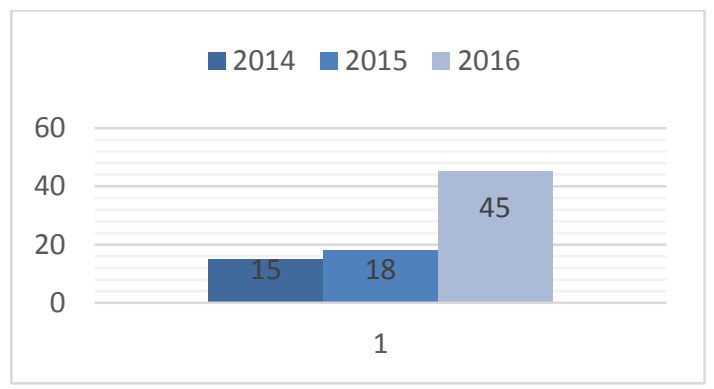

Gambar 1. Perbandingan jumlah penderita OMSK yang datang ke Poliklinik THT-KL RSUP Prof. Dr. R. D. Kandou Manado per tahun selama periode $2014-2016$

Jumlah penderita OMSK berjenis kelamin perempuan dan laki-laki seimbang yaitu masing-masing sebanyak 39 orang yang berobat ke Poliklinik THT-KL RSUP Prof. Dr. R. D. Kandou Manado periode Januari 2014 - Desember 2016 (Gambar 2). 


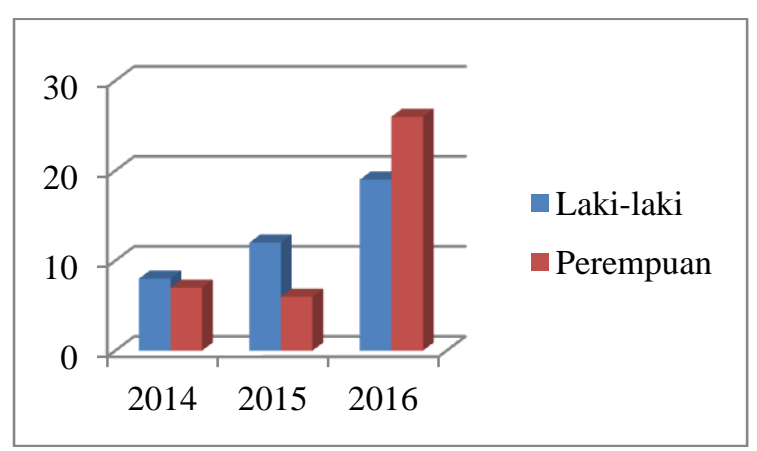

Gambar 2. Perbandingan angka kejadian penderita OMSK jenis kelamin laki-laki dan perempuan berdasarkan tahun kejadian.

Berdasarkan hasil penelitian, didapatkan usia 18-40 tahun yang paling banyak menderita OMSK, yaitu 30 penderita (38\%), diikuti usia 41-65 tahun sebanyak 18 orang (23\%); usia 12-17 tahun dengan 9 orang (12\%), usia 6-11 tahun dengan 8 orang (10\%); usia $>65$ tahun dengan 7 orang (9\%); dan yang terakhir $<5$ tahun dengan 6 orang (8\%) (Gambar 3).

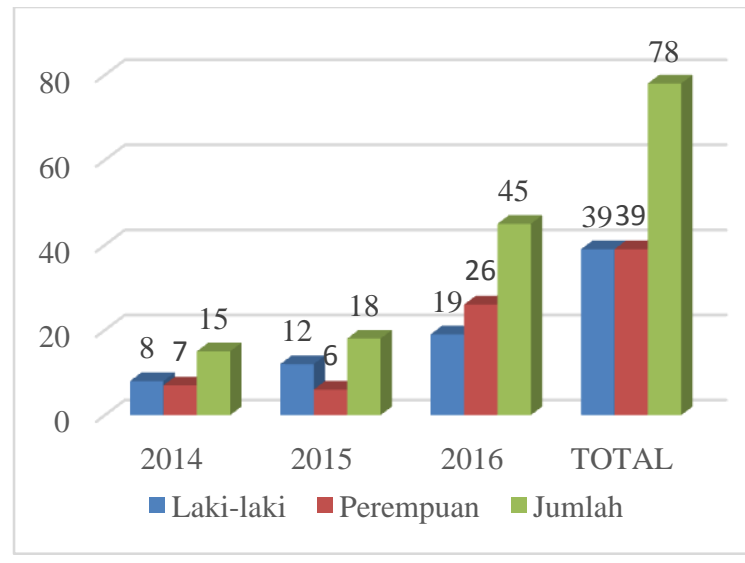

Gambar 3. Jumlah penderita OMSK berdasarkan golongan usia

Berdasarkan data hasil penelitian, didapatkan bahwa sebagian besar penderita OMSK belum bekerja, tidak bekerja, atau tidak bekerja lagi, dengan jumlah 23 orang (28\%), kemudian secara bersamaan diikuti oleh penderita yang bekerja sebagai pelajar, swasta dan IRT masing-masing 15 orang (19\%); PNS sebanyak 6 orang (8\%), dan buruh sebanyak 1 orang (1\%) (Gambar 4).

Dari data yang telah dikumpulkan, didapatkan 6 gejala yang paling sering menjadi keluhan yang membawa pasien berobat ke Poliklinik THT-KL RSUP Prof.
Dr. R. D. Kandou Manado. Sebanyak 68 penderita $(87 \%)$ mengalami otore, diikuti oleh berkurangnya pendengaran pada 28 orang (35\%), otalgia pada 26 orang (33\%), nyeri kepala dialami oleh 13 orang $(17 \%)$, demam pada 11 orang (14\%), batuk serta pilek dialami 10 orang (12\%), dan gejala lainnya yang dialami oleh 12 orang (15\%).

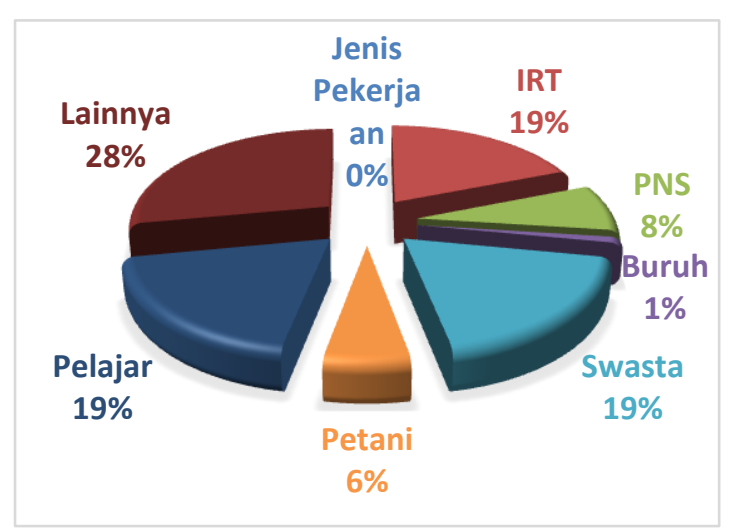

Gambar 4. Perbandingan pekerjaan dari penderita OMSK yang datang ke Poliklinik RSUP Prof. Dr. R. D. Kandou Manado periode Januari 2014 - Desember 2016

Hasil penelitian menunjukkan bahwa lokasi OMSK unilateral didapatkan pada 60 penderita (77\%), sedangkan lokasi bilateral pada 18 penderita (23\%) (Gambar 5).

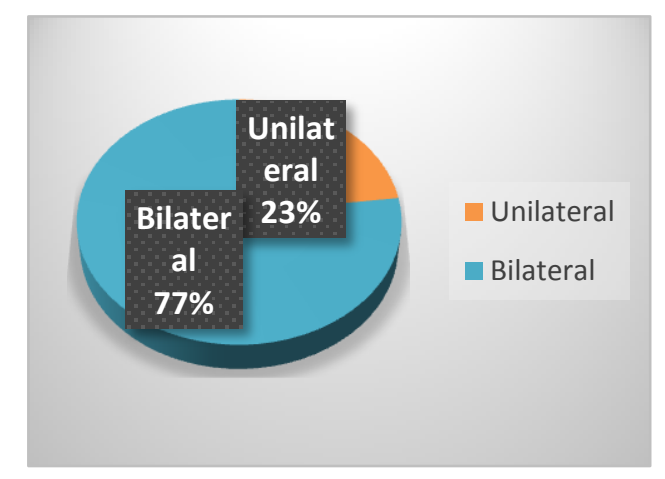

Gambar 5. Jumlah penderita OMSK berdasarkan lokasi

Penanganan medikamentosa merupakan jenis penanganan yang paling sering ditemukan yaitu sebanyak 60 penderita (77\%), sedangkan penanganan dengan tindakan bedah didapatkan pada 18 penderita (23\%) (Gambar 6). 


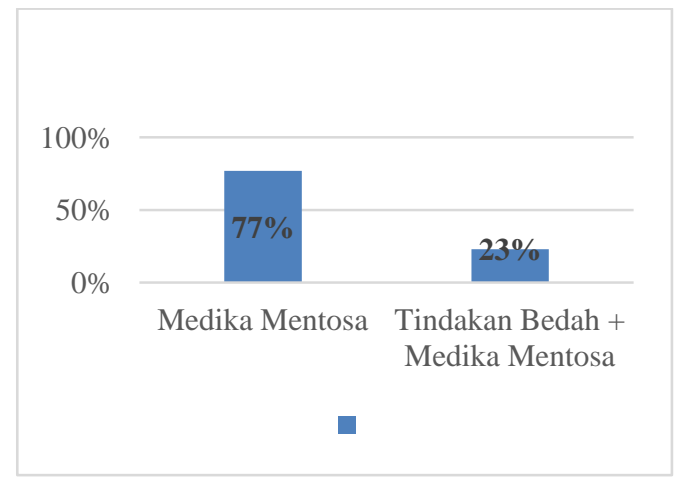

Gambar 6. Perbandingan berdasarkan jenis penanganan

\section{BAHASAN}

Berdasarkan hasil penelitian ditemukan 78 kasus dengan diagnosis OMSK yang datang berobat di Poliklinik THT-KL RSUP Prof. Dr. R. D. Kandou Manado periode Januari 2014-Desember 2016, dengan kasus terbanyak pada tahun 2016 yaitu sebanyak 45 kasus, dan yang paling sedikit yaitu tahun 2014 dengan 15 kasus, sedangkan tahun 2015 didapatkan 18 kasus (Gambar 1). Dapat dilihat bahwa OMSK di Poliklinik THT-KL mengalami peningkatan jumlah penderita setiap tahunnya. Hal ini mungkin berkaitan dengan kurangnya kesadaran masyarakat akan kebersihan individu, sanitasi lingkungan, dan kurangnya pengetahuan masyarakat akan pentingnya menjaga kesehatan telinga dan penyakit OMSK itu sendiri.

Berdasarkan distribusi jenis kelamin, dapat dilihat bahwa tidak ada perbedaan antara penderita laki-laki dan perempuan, yaitu masing-masing berjumlah $50 \%$ (Gambar 2). Hal ini menunjukkan bahwa jenis kelamin bukan suatu faktor risiko penyakit OMSK.

Distribusi usia menunjukkan bahwa kelompok 18-40 tahun merupakan usia tersering menderita OMSK dengan jumlah 30 penderita (Gambar 3). Hal ini berarti sebagian penderita berada dalam usia produktif; kemungkinan penderita kurang memperhatikan higienitas, sanitasi, bahkan pentingnya kesehatan.

Data mengenai distribusi berdasarkan pekerjaan menunjukkan bahwa pada perio- de Januari 2014-Desember 2016, pelajar, swasta, dan IRT paling sering menderita OMSK yaitu masing-masing sebanyak 15 penderita (19\%) (Gambar 4). Hal ini mungkin masih berkaitan dengan usia dan kurangnya perhatian terhadap higienitas, sanitasi, dan kurangnya kesadaran akan betapa pentingnya kesehatan diri serta berhubungan dengan sosial ekonomi masyarakat.

Hasil penelitian menunjukkan bahwa gejala klinik yang paling sering membawa penderita berobat ialah keluarnya cairan dari telinga (otore) yang ditemukan pada 68 penderita (87\%), disertai dengan gangguan pendengaran dan nyeri telinga. Hal ini mungkin terjadi karena kurangnya pengetahuan masyarakat tentang penyakit ini, sehingga masyarakat tidak dapat mengenali gejala awal dari OMSK. Selain itu, keluhan yang menyertai ialah nyeri kepala, batuk, pilek, demam, dan gejala lainnya.

Data hasil penelitian memperlihatkan bahwa kasus OMSK pada satu telinga (unilateral) lebih tinggi dibandingkan OMSK pada kedua telinga (bilateral), yaitu pada unilateral berjumlah 60 penderita (77\%), sedangkan bilateral sebanyak 18 penderita (23\%) (Gambar 5).

Hasil penelitian menunjukkan jenis penanganan medikamentosa berupa pemberian antibiotika, analgetik, dan obat lainnya merupakan jenis penanganan yang paling sering diberikan yaitu sebanyak 60 penderita $(77 \%)$, sedangkan yang mendapatkan tindakan bedah sebanyak 18 penderita (23\%) (Gambar 6). Hasil ini menunjukkan bahwa sesuai dengan literatur, penanganan OMSK biasanya dimulai dengan pemberian antibiotic. $^{10-13,15}$

Tindakan bedah yang paling sering dilakukan ialah mastoidektomi. Hal ini sesuai dengan literatur, dilakukan untuk membuang jaringan patologik, mencegah komplikasi, serta mempertahankan fungsi pendengaran yang masih ada. ${ }^{9,12,14,15}$

\section{SIMPULAN}

Berdasarkan hasil penelitian ini dapat disimpulkan bahwa OMSK terbanyak didapatkan pada usia 18-40 tahun dan tidak 
terdapat perbedaan pada kedua jenis kelamin. Otore merupakan gejala klinik yang paling sering, diikuti oleh otalgia dan pendengaran berkurang. Umumnya lokasi OMSK unilateral dan jenis penanganan tersering ialah medikamentosa.

\section{SARAN}

Disarankan untuk meningkatkan kualitas pengisian data rekam medis dan penyempurnaan dalam sistem pencatatan dan penyimpanan data pasien.

\section{DAFTAR PUSTAKA}

1. Kolegium Ilmu Kesehatan Telinga Hidung Tenggorok Bedah Kepala dan Leher. Radang telinga tengah. Modul THTKL. Jakarta: Perhati-KL, 2008.

2. Telian SA. Chronic otitis media. In: Schmalbagh CE, editor. Disease of the Nose, Throat, Ear, Head, and Neck (16th ed). Philadelphia: Ballenger, 2009; p. 261-70.

3. Helmi. Otitis Media Supuratif Kronis (2nd ed). Jakarta: Balai Penerbitan FK UI, 2006.

4. Tiedt NJ, Butler IRT, Hallbauer UM, Atkins MD, Elliot E, Pieters M, et al. Pediatric chronic suppurative otitis media in the free state province: clinical and audiological features. S Afr Med J. 2013;103(7):467-70.

5. Kaur K, Sonkhya N. Chronic suppurative otitis media and sensorineural hearing loss: is there a correlation? Indian J Otolaryngol Head Neck Surg. 2003; 55(1):23-30.

6. Gould JM, Matz PS. Otitis media. Pediat Rev. 2010;31(3):102-10.

7. Departemen Kesehatan RI. Pedoman upaya kesehatan telinga dan pencegahan gangguan pendengaran untuk puskesmas. Jakarta : Depkes RI, 2003.

8. Aboet A. Radang telinga tengah menahun.
Pidato Pengukuhan Jabatan Guru Besar Tetap Bidang Ilmu Kesehatan Telinga Hidung Tenggorok Bedah Kepala Leher. Medan: Fakultas Kedokteran Universitas Sumatera Utara; 2007.

9. Bhat KV, Naseeruddin K, Nagalothimath US, Kumar PR, Hedge JS. Cortical mastoidectomy in quiescent, tubotympanic, chronic otitis media: Is it routinely necessary? J Laryngol Otol. 2009;123;383-90.

10. Nursiah S. Pola kuman aerob penyebab omsk dan kepekaan terhadap beberapa antibiotik di Bagian THT FK USU/ RSUP H. Adam Malik Medan. Medan: FK USU; 2003.

11. WHO. Chronic suppurative otitis media burden off illness and management option. In: Child and Adolescent Health and Development Prevention of Blindness and Dearness. Geneva: WHO, 2004.

12. Parry D, Roland PS. Middle ear, chronic suppurative otitis, medical treatment. 2005. [cited 2017 Sept 9]. Available from: www.emedicine.com: situs internet.

13. Jackler RK, Kaplan MJ. Ear, nose, \& throat. In: Tierney LM, McPhee SJ, Papadakis MA, editors. Current Medical Diagnosis \& Treatment. San Fransisco: Lange Medical Books/ McGraw-Hill, 2002

14. Jain A, Knight JR. 2003. Middle ear, chronic suppurative otitis, surgical treatment. [cited 2017 Sept 9]. Available from: www.emedicine.com: situs internet.

15. Roland PS, Isaacson B, Meyers AD. Chronic suppurative otitis media treatment \& management. Texas: Southwestern Medical Center University of Texas, 2015. 